\title{
TOPSİS Çok Kriterli Karar Verme Yöntemi ile Güneş Enerjisi Sistemlerinde Panel Seçimi
}

\author{
Fulya Aslay $^{1 *}$

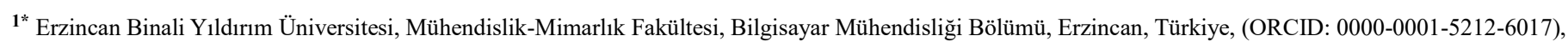 \\ faslay@erzincan.edu.tr
}

(1st International Conference on Applied Engineering and Natural Sciences ICAENS 2021, November 1-3, 2021)

(DOI: 10.31590/ejosat.1008727)

\begin{abstract}
ATIF/REFERENCE: Aslay, F. (2021). TOPSíS Çok Kriterli Karar Verme Yöntemi ile Güneş Enerjisi Sistemlerinde Panel Seçimi. Avrupa Bilim ve Teknoloji Dergisi, (28), 548-551.

Öz

Fosil kaynaklı yakıtların gün geçtikçe tükenmesi sebebiyle yenilenebilir enerji kaynaklarının önemi de gittikçe artmaktadır. Güneş enerjisi teknolojisi, mevcut yenilenebilir enerji kaynakları arasında en hızlı büyüyen ve en popüler olanlardan biridir. Fotovoltaik (PV) sistemler olarak da bilinen güneş enerjisi sistemleri, güneş 1şınımının evrensel olarak kullanılabilirliği ve PV panelini tüketici tarafında kurma esnekliği nedeniyle en çok aranan yenilenebilir enerji kaynağıdır. Ülkemizde son yıllarda popülerliği giderek artan güneş enerjisi sistemleri genelde ticari amaçlı ve çatı tipi denilen evsel uygulamalarda yaygın olarak kullanılmaktadır. Monokristal, perc monokristal, polikristal, ince film ve yarı esnek olmak üzere beş tip güneş paneli bulunmaktadır. Kullanıcıların bu farklı hücre tipine sahip panellerden hangisini kullanacağına karar vermesi aşamasında göz önünde bulundurduğu ve öncelik verdiği parametreler bulunmaktadır. Bu parametreler doğrultusunda kullanıcıların kendilerine en uygun güneş panelini belirlemeleri her zaman gözle ve kısa sürede mümkün olmayabilir. Bu çalışmada çok kriterli karar verme yöntemlerinden TOPSíS ile kullanıcıların kendi belirledikleri önem derecelerine göre maliyet, sıcaklık katsayısı ve enerji verimliliği açısından en uygun güneş paneli seçimlerine yardımcı olmak için bir model gerçekleştirilmiştir. Bu model sayesinde evsel uygulamalarda kullanıcıların kendi tercihlerine en uygun olan güneş panelleri sıralanarak kullanıcılara liste halinde sunulmakta ve böylece en optimum ürüne karar verme işlemi başarıyla ve mümkün olan en kısa sürede sağlanmaktadır.
\end{abstract}

Anahtar Kelimeler: Çok kriterli karar verme, Güneş enerjisi, TOPSİS, Güneş paneli, Enerji verimliliği.

\section{Photovoltaic Panel Selection in Solar Energy Systems with TOPSIS Multi-Criteria Decision Making Method}

\begin{abstract}
The importance of renewable energy sources is increasing day by day due to the depletion of fossil fuels. Solar technology is one of the fastest growing and most popular renewable energy sources available.Solar power systems, also known as photovoltaic (PV) systems, are the most sought-after renewable energy source due to the universal availability of solar radiation and the flexibility to install the PV panel on the consumer side. Solar energy systems, which have become increasingly popular in our country in recent years, are generally used for commercial purposes and in domestic applications called roof type.There are five types of solar panels which names are monocrystalline, perc monocrystalline, polycrystalline, thin film and semi-flexible.There are parameters that users consider and prioritize when deciding which of these panels with different cell types to use.In line with these parameters, it may not always be possible for users to determine the most suitable solar panel visually and in a short time.In this study, a model has been developed with TOPSIS, one of the multi-criteria decision-making methods, to help the users choose the most suitable solar panel in terms of cost, temperature coefficient and energy efficiency according to their own importance.Due to this model, the solar panels that are most suitable for the users' own preferences in domestic applications are listed and presented to the users in a list, so that the most optimum product is decided successfully also in the shortest possible time.
\end{abstract}

Keywords: Multi-criteria decision making, Solar energy, TOPSIS, Solar panel, Energy efficiency.

\footnotetext{
* Sorumlu Yazar: faslay@erzincan.edu.tr
} 


\section{Giriş}

Fosil kaynaklı yakıtların gün geçtikçe tükenmesi sebebiyle yenilenebilir enerji kaynaklarının önemi de gittikçe artmaktadır. Güneş enerjisi teknolojisi, mevcut yenilenebilir enerji kaynakları arasında en hızlı büyüyen ve popüler olanlardan biridir. Güneş enerjisi üretimi, yarı iletken ara yüzünün fotovoltaik (PV) etkisini kullanarak 1 şı enerjisini doğrudan elektrik enerjisine çeviren bir teknolojidir. Güneş pilleri bu teknolojinin en önemli anahtar unsurudur. Bir dizi güneş pili kapsüllenmiş korumadan sonra, bir fotovoltaik sistem cihazı oluşturmak için güç kontrolörü ve diğer bileşenlerle birleştiğinde geniş alanlı bir güneş paneli modülü oluşturur. Fotovoltaik (PV) sistemler olarak da bilinen güneş enerjisi sistemleri, güneş 1şınımının evrensel olarak kullanılabilirliği ve PV panelini tüketici tarafinda kurma esnekliği nedeniyle en çok aranan yenilenebilir enerji kaynağıdır [1-3]. Ülkemizde son yıllarda popülerliği artan güneş enerjisi sistemleri genelde ticari amaçlı ve çatı tipi denilen evsel uygulamalarda kullanılmaktadır.

Güneş enerjisinden maksimum şekilde yararlanabilmek için kurulum esnasında dikkat edilmesi gereken en önemli parametrelerden biri hiç şüphesiz güneş paneli tercihidir. Özellikle çatı tipi güneş enerji sistemlerinde panel verimliliği oldukça önem arz etmektedir. Kullanıcıların kurulum esnasında doğru panel seçimi yapabilmesi güneş enerjisinden maksimum boyutta faydalanabilmek için önemli bir husustur [4-6].

Güneş paneli seçiminde dikkat edilecek birçok unsur vardır. Bunlar; maliyet, panel kalitesi, enerji verimliliği, güneş paneli sıcaklık katsayısı, panel kullanım ömrü, panel gücü ve güneş paneli hücre tipidir. Günümüzde yaygın olarak kullanılan beş tip güneş paneli vardır. Bunlar monokristal, perc monokristal, polikristal, ince film ve yarı esnek güneş panelleridir. Panel üzerindeki güneş hücrelerinin malzeme yapısına göre farklılık gösteren bu panellerin performans ve enerji verimliliği de farklılık göstermektedir. Dolayısıyla kullanıcıların bu farklı hücre tipine sahip panellerden hangisini kullanacağına karar vermesi aşamasında göz önünde bulunduracağı ve öncelik verdiği parametreler önem arz etmektedir. Yukarıda bahsedilen bu parametrelerden panel kullanım ömrü, panel kalitesi ve panel gücünün aynı şartlarda olduğu düşünülerek kullanıcılar genellikle maliyet, güneş paneli sıcaklık katsayısı ve enerji verimliliği açısından bir karar vererek bir tercihte bulunmaktadır.

Güneş paneli tercihinde önemli kriterlerden biri olan sıcaklık katsayıs1 \% /oC birimi ile ifade edilen ve panelin enerji üretiminin sıcaklıktan ne ölçüde etkileneceğini anlatan bir değerdir. Güneş panelleri elektrik enerjisi üretirken, güneşten alınan ışınımın bir kısmı elektrik enerjisine dönüşürken bir kısmı da 1sıya dönüşür. Dolayısıyla paneller de ister istemez 1sınmaktadır. Güneş panel hücrelerinin 1sınmasıyla birlikte akım değeri artarken gerilim değeri de düşmektedir. Gerilimde meydana gelen bu düşüş ile panel gücü düşmekte ve güneş paneli daha az elektrik enerjisi üretmektedir. Dolayısıyla güneş panellerinden daha fazla enerji üretimi yapılabilmesi adına güneş paneli sıcaklık katsayısının düşük olması istenir.

Kullanıcıların tercihte bulunurken dikkat edeceği diğer iki parametreden biri olan maliyetin düşük, enerji verimliliğinin de doğal olarak yüksek olması istenir. Enerji verimliliği, 1şınımın elektrik enerjisine dönüştürülme oranı olarak da tanımlanabilir. Enerji verimliliği ile maliyet arasında doğrun orantı bulunmakta ve verim arttıkça panel fiyatlarının da arttığı bilinmektedir. Ancak en verimli panelin en iyi panel anlamına gelmeyeceği de göz önünde bulundurularak bu çalışma da kullanıcıların enerji verimliliği, maliyet ve güneş paneli sıcaklık katsayısı açısından tercih yaparken çok kriterli karar verme (ÇKKV) yöntemlerinden faydalanılarak bir model geliştirilmiştir. ÇKVV yöntemleri literatürde birçok alanda olduğu gibi yenilebilir enerji kaynakları için de çok kriterli alternatiflerin değerlendirmesinde sıklıkla kullanılmaktadır. [7] numarada sunulan çalışmada, TOPSIS yöntemi kullanarak Türkiye'de yenilenebilir enerji kaynakları içerisinden en uygun olanı belirlemeye çalışmışlardır. [8] numaralı çalışmada İran'daki bir bölgede sürdürebilirliği sağlamak için 18 farklı kriter TOPSIS yöntemi ile kıyaslanmıştır. [9] numaralı çalışmada, TOPSIS yöntemi kullanarak Pakistan için güneş, hidroelektrik, biyokütle, rüzgâr ve jeotermal enerji için sıralama yapılmıştır.

\section{TOPSISS Çok Kriterli Karar Verme Yöntemi}

Karar vericilere karar vermelerinde yardımcı olabilmek için çok kriterli karar verme yöntemleri ilk olarak 1960lı yıllarda geliştirilmeye başlanmıştır. Karar verme işlemi; anlama, tasarım, seçim ve uygulama olmak üzere dört aşamalı çok adımlı bir süreç olarak tanımlanmaktadır [10]. Öncelikle problemin nerede olduğu anlaşıldıktan sonra probleme yönelik farklı çözümler tasarlanıp alternatif çözümler içerisinden biri belirlenerek uygulanır ve çözümün problem üzerindeki etkisi belirlenir. Eğer çözüm yeterince etkin değilse karar verme aşamalarından bir önceki aşamaya dönülür ve gerektiğinde bu geri dönüşler tekrarlanır [11].

Çok kriterli karar verme yöntemleri özellikle alternatif ve kriter sayısının fazla olduğu problemlerde her bir alternatifin birlikte değerlendirilmesiyle uygulanarak nitel ve nicel kriterlere göre kararların daha hızlı ve kolay bir şekilde verilmesini sağlamaktadırlar [12-14]. AHP, ANP, Topsis, Electre, Maut, Vikor, Uta, Promethee, Gra, Dematel, Moora gibi çok kriterli karar verme yöntemleri günlük hayatımızda verilen kişisel kararlardan işletmelerin stratejik ve kritik kararlarına kadar birçok farklı alanda uygulanmaktadır.

ÇKKV yöntemlerinden biri olan TOPSIS methodu Hwang ve Yoon tarafindan 1981 yılında geliştirilmiştir [15]. Bu teknik ideal çözüme en yakın, ideal olmayan çözüme de en uzak olan önceliği belirlemek için kullanılır. Önce karar matrisi vektör normalizasyonuna göre normalize edilir böylece ideal olan ve olmayan çözümler bu normalize edilmiş matris üzerinden tanımlanır [16]. TOPSIS metodunda alternatifler, pozitif ideal çözüme en yakın, negatif ideal çözümden ise en uzak olmaları yönünden değerlendirilerek sıralanırlar. $\mathrm{Bu}$ yakınlık Öklid uzaklığı kullanılarak belirlenir. TOPSIS yöntemi hesaplamadaki basitliği, rasyonelliği ayrıca kolay kavranabilirliği ve değerlendirme kriterlerinin ağırlıklandırılmasına imkân vermesi nedeniyle literatürde en çok kullanılan tekniklerden biridir [17]. Az sayıda parametre ile değerlendirme yapılabildiğinden TOPSIS yöntemi en çok tercih edilen ÇKVV yöntemlerinden biri olup tek başına bazen de diğer yöntemlerle bütünleşik olarak kullanılabilir. Burada her bir parametrenin ölçeği aynı birim üzerinden olmalidir.

\section{Uygulama}

$\mathrm{Bu}$ çalışmada karar verme için kullanılacak kriterlerin tek düze artışı ve tek düze azalışları olduğundan ÇKVV yöntemleri içerisinden TOPSIS yöntemi tercih edilmiştir. TOPSIS 
yönteminde alternatif seçenekler kendi aralarında minimum ve maksimum değerler arasındaki ideal olma durumlarına göre karşılaştırılarak sıralanırlar.

Çalışmada kullanılan güneş panelleri türleri Tablo 1'de, seçim kriterleri olan maliyet, sıcaklık katsayısı ve verim parametreleri için TOPSIS ideal çözüm hedefleri ise Tablo 2'de sunulmaktadır.

Tablo 1. Güneş Paneli Türleri

\begin{tabular}{|c|c|}
\hline Alternatif & Güneş Paneli Türü \\
\hline$A 1$ & İnce Film Esnek \\
\hline$A 2$ & Yarı Esnek \\
\hline$A 3$ & Monokristal \\
\hline$A 4$ & Polikristal \\
\hline$A 5$ & Perc monokristal \\
\hline
\end{tabular}

Tablo 2. Güneş Paneli Seçim Kriterleri

\begin{tabular}{|c|c|c|c|}
\hline Kriter & $\begin{array}{c}\text { Karar } \\
\text { Parametresi }\end{array}$ & $\begin{array}{c}\text { TOPSIS İdeal } \\
\text { Çözü̈m Hedefi }\end{array}$ & Ăğırlı̆̆ı \\
\hline$K 1$ & Maliyet & Minimum & 0,45 \\
\hline$K 2$ & Sicaklık Katsayısı & Minimum & 0,25 \\
\hline$K 3$ & Verim & Maksimum & 0,30 \\
\hline
\end{tabular}

Belirlenen güneş paneli türleri içim seçim kriterlerine göre belirlenen karar matrisi Tablo 3'de sunulmaktadır.

\section{Tablo 3. Karar Matrisi}

\begin{tabular}{|c|c|c|c|}
\hline Alternatif & $\boldsymbol{K 1}$ & $\boldsymbol{K 2}$ & $\boldsymbol{K 3}$ \\
\hline$A 1$ & 3109 & 0,38 & 16,5 \\
\hline$A 2$ & 2206 & 0,31 & 24,8 \\
\hline$A 3$ & 812 & 0,41 & 19,68 \\
\hline$A 4$ & 602 & 0,45 & 17,25 \\
\hline$A 5$ & 900 & 0,39 & 20,2 \\
\hline
\end{tabular}

Karar matrisinde, değerlendirme kriterleri TOPSIS yöntemi ile analiz edilmiştir. Her kriterin önem derecesi olan ağırlıkları verilen karar matrisi örneği için farklı kabul edilmiştir. Buna göre kullanıcı tarafından maliyetin 0,45 bununla birlikte sicaklık katsayısının 0,25 ve verimin 0,30 önem derecesi ile belirlendiği kabul edilmiştir. İdeal çözüme mutlak yakınlık değeri olan $C^{*}$ değeri, çalışmada Microsoft Excel programı aracılığıyla hesaplanmıştır. $C^{*}$ değeri ne kadar büyükse o panel türü o derece iyi bir alternatiftir. TOPSIS yönteminin işlem basamakları aşağıda yer almaktadır $[18,19]$.

Adım 1: Karar matrisi oluşturulur. Burada satırlarda seçime karar verilecek alternatifler sütunlarda ise değerlendirmeye tabi tutulan parametreler belirlenir.

Adım 2: Karar matrisinde bulunan kriterler normalize edilir. Bunun için kriterlere ait değerlerin karelerinin toplamının karekökü alınarak tüm kriterler -1 ile +1 arasında değer alırlar. Burada i satırları ve $\mathrm{j}$ sütunları göstermek üzere normalizasyon işlemi;

$$
Z_{i j}=\frac{y_{i j}}{\sqrt{\sum_{i=1}^{n} y_{i j}^{2}}}
$$

$(i=1, \ldots \ldots, n ; j=1, \ldots \ldots ., k)$

Buna göre çalışmada veri seti içerisinde bulunan tüm değerler Tablo 4'de olduğu gibi normalize edilmiştir.

Tablo 4. Normalize Edilmiş Karar Matrisi

\begin{tabular}{|c|c|c|c|}
\hline Alternatif & $\boldsymbol{K} \mathbf{1}$ & $\boldsymbol{K} \mathbf{2}$ & $\boldsymbol{K} 3$ \\
\hline$A 1$ & 0,77 & 0,43 & 0,37 \\
\hline$A 2$ & 0,55 & 0,35 & 0,56 \\
\hline$A 3$ & 0,20 & 0,47 & 0,44 \\
\hline$A 4$ & 0,15 & 0,52 & 0,39 \\
\hline$A 5$ & 0,22 & 0,45 & 0,45 \\
\hline
\end{tabular}

Adım 3: Kriterlerin önem derecesine göre karar matrisindeki tüm kriterler ağırlıklandırılır. Tüm kriter ağırlıklarının toplamı 1'e eşit olmalıdır. Ağırlıklı normalize edilmiş karar matrisi Tablo 5'de sunulmaktadır. Buna göre karar verme kriterlerinden maliyet $\% 45$, sicaklık tolerans 0,25 verim ise $\% 30$ oranında karar vermeyi etkilemektedir.

Tablo 5. Ă̆ırlıklı Normalize Edilmiş Karar Matrisi

\begin{tabular}{|c|c|c|c|}
\hline Alternatif & $K 1$ & $K 2$ & $K 3$ \\
\hline$A 1$ & 0,77 & 0,43 & 0,37 \\
\hline$A 2$ & 0,55 & 0,35 & 0,56 \\
\hline$A 3$ & 0,20 & 0,47 & 0,44 \\
\hline$A 4$ & 0,15 & 0,52 & 0,39 \\
\hline$A 5$ & 0,22 & 0,45 & 0,45 \\
\hline 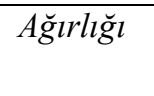 & $\begin{array}{c}0,45 \\
\text { (minimum) }\end{array}$ & $\begin{array}{c}0,25 \\
\text { (minimum) }\end{array}$ & $\begin{array}{c}0,30 \\
\text { (maksimum) }\end{array}$ \\
\hline
\end{tabular}

Adım 4: pozitif ideal çözüm $\mathrm{A}^{+}$ve negatif ideal çözüm $\mathrm{A}^{-}$ noktaları tanımlanır. Bunun için ağırlıklandırılmış karar matrisindeki her bir sütunun maksimum ve minimum değerleri tespit edilir.

$$
\begin{aligned}
& \mathrm{A}^{+}=\left\{\mathrm{x}^{+}, \mathrm{x} 2^{+}, \ldots \ldots . ., \mathrm{xk}^{+}\right\}: \text {maksimum değerler, } \\
& \mathrm{A}^{-}=\left\{\mathrm{x} 1^{-}, \mathrm{x} 2^{-}, \ldots \ldots . ., \mathrm{xk}^{-}\right\}: \text {minimum değerlerdir. }
\end{aligned}
$$

Buna göre veri setinde hesaplanan $\mathrm{A}^{+}$ve $\mathrm{A}^{-}$değerleri Tablo 6'da sunulmaktadır.

Tablo 6. Pozitif ve Negatif İdeal Çözüm Değerleri

\begin{tabular}{|c|c|c|c|}
\hline & K1 & K2 & K3 \\
\hline Pozitif İdeal Çözüm $(A+)$ & 0,35 & 0,13 & 0,17 \\
\hline Negatif Iddeal Çözüm $(A-)$ & 0,07 & 0,09 & 0,11 \\
\hline
\end{tabular}

Adım 5: Pozitif ideal noktaya uzaklık olan $\mathrm{S}_{\mathrm{i}}^{+}$ve negatif ideal noktaya uzaklık olan $\mathrm{S}_{\mathrm{i}}^{-}$hesaplanır;

$$
S_{i}^{+}=\sqrt{\sum_{j=1}^{k}\left(x_{i j}-x_{j}^{+}\right)^{2}}
$$

Adım 6: Karar matrisindeki her bir alternatifin ideal çözüme göre göreceli yakınlık değeri olan $\mathrm{C}_{\mathrm{i}}^{+}$hesaplanır. Yakınlık katsayısı - ve 1 arasında değer alıp yakınlık katsayısı en yüksek hesaplanan alternatif seçime en uygun alternatif olarak belirlenir. Daha sonra tüm alternatifler ideal çözüme yakınlık değerlerine göre büyükten küçüğe doğru sıralanırlar. 


$$
S_{i}^{-}=\sqrt{\sum_{j=1}^{k}\left(x_{i j}-x_{j}^{-}\right)^{2}}
$$

$(\mathrm{i}=1, \ldots \ldots, \mathrm{n})$

$$
\mathrm{C}_{\mathrm{i}}^{+}=\mathrm{S}_{\mathrm{i}}^{-} / \mathrm{S}_{\mathrm{i}}^{+}+\mathrm{S}_{\mathrm{i}}^{-}, 1 \geq \mathrm{C}_{\mathrm{i}} \geq 0 \quad(\mathrm{i}=1, \ldots \ldots, \mathrm{n})
$$

Buna göre hesaplanan pozitif ideal noktaya uzaklık olan $\mathrm{S}_{\mathrm{i}}^{+}$ ve negatif ideal noktaya uzaklık olan $\mathrm{S}_{\mathrm{i}}^{-}$değerleri ile göreli yakınlık değerleri $C^{*}$ Tablo 7'de sunulmaktadır;

\section{Tablo 7. İdeal Çözüme Göre Yakınlıv ve Göreli Yakınlık Değerleri}

\begin{tabular}{|l|l|l|l|}
\hline Alternatif & $\boldsymbol{S}^{+}$ & $\boldsymbol{S}^{-}$ & $\boldsymbol{C}^{*}$ \\
\hline$A 1$ & 0,0594 & 0,2796 & 0,8247 \\
\hline$A 2$ & 0,1081 & 0,1870 & 0,6336 \\
\hline$A 3$ & 0,2581 & 0,0427 & 0,1420 \\
\hline$A 4$ & 0,2835 & 0,0404 & 0,1247 \\
\hline$A 5$ & 0,2483 & 0,0474 & 0,1603 \\
\hline
\end{tabular}

Beş tipte ele alınan güneş panellerinin belirlenen kriterlere göre TOPSIS yöntemi ile değerlendirmesi sonucunda kullanıcılar açısından tercih edilebilirliği $\mathrm{A} 1>\mathrm{A} 2>\mathrm{A} 5>\mathrm{A} 3>\mathrm{A} 4$ olarak bulunmuştur. Buna göre ince film esnek, yarı esnek, monokristal, polikristal ve perc monokristal olmak üzere beş farklı hücre tipine sahip güneş paneli içerisinden; maliyet ve sıcaklık katsayısının minimum, verimin ise maksimum olmasının tercihine göre ince film esnek güneş paneli en iyi, polikristal güneş paneli ise kullanıcının tercihine en az uygun alternatif olarak belirlenmiştir.

\section{Sonuçlar}

Yenilenebilir enerji sistemlerinden en yaygın olarak kullanılanlarından biri de güneş enerjisi sistemleridir. Güneş enerjisi üretiminde kullanılan güneş panelleri farklı yapılarda üretilmekte ve ihtiyaca göre tercih sebebi değişebilmektedir. Kullanıcılar güneş paneli seçiminde genellikle niteliksel ve niceliksel kriterleri göz önünde bulundurmaktadır. Dolayısıyla kullanıcıların bu kriterler arasından kendi tercihlerine göre kısa sürede seçim yapabilmeleri önemli bir kolaylaştırıcı unsurdur. $\mathrm{Bu}$ çalışmada güneş paneli seçiminde belirlenen kriterlere göre alternatiflerin değerlendirildiği ve kullanıcılara karar vermelerinde yardımcı olabilmek için çok kriterli karar verme yöntemlerinden TOPSİS kullanılmıştır. TOPSİS ile geliştirilen model Monokristal, perc monokristal, polikristal, ince film ve yarı esnek olmak üzere beş farklı hücre tipine sahip güneş panellerinden kullanıcılara kendi belirledikleri önem derecelerine göre maliyet, sıcaklık katsayısı ve enerji verimliliği açısından en uygun güneş paneli seçmelerine yardımcı olmaktadır. Böylece kullanıcıların seçimlerini daha kısa sürede ve doğru bir şekilde yapabilmeleri sağlanmaktadır.

\section{Kaynakça}

[1] R. Foster, M. Ghassemi and A. Cota, "Solar Energy, Renewable Energy and the Environmental", CRC Press Taylor \& Francis Group, Boca Raton, ISBN 978-1-4200- 7566-3, 2010.

[2] W. Charters, "Developing markets for renewable energy technologies," Journal of Renewable Energy, vol. 22, no. 1-3, pp. $217-222,2001$
[3] T. Esram and P. L. Chapman, "Comparison of photovoltaic array maximum power point tracking techniques," IEEE Transactions on Energy Conversion, vol. 22, no. 2, pp. 439- 449, 2007.

[4] Balo, F., and Sagbansua, L., "The selection of the best solar panel for the photovoltaic system design by using AHP", Energy Procedia, vol. 100, pp. 50-53, 2016.

[5] Wang, C.-N., Nguyen, V.T. and Hoang, D.H.D., "Multi-criteria decision making (MCDM) approaches for solar power plant location selection in Vietnam”, Energies, vol 11, pp. 1504-1508, 2018.

[6] Wang, T.C. and Tsai, S.Y., "Solar Panel Supplier Selection for the Photovoltaic System Design by Using Fuzzy Multi-Criteria Decision Making (MCDM) Approaches", Energies, vol 11, pp. 1989-1998, 2018

[7] Trappey, A.J., Trappey, C.V., Wang, D.Y., Ou, J.J. and Li, S.J., "An Integrated Self-Organizing Map and Analytic Hierarchy Process Modeling Approach for Evaluating Renewable Energy Polices", International Journal of Electronic Business Management, vol. 13, pp. 3-14, 2015.

[8] Aryanpur, V., Atabaki, M. S., Marzband, M., Siano, P. and Ghayoumi, K., "An overview of energy planning in Iran and transition pathways towards sustainable electricity supply sector", Renewable and Sustainable Energy Reviews, vol. 112, pp. 58-74, 2019.

[9] Solangi, Y. A., Tan, Q., Mirjat, N. H., Valasai, G. D., Khan, M. W. A. and Ikram, M. "An Integrated DelphiAHP and Fuzzy TOPSIS Approach toward Ranking and Selection of Renewable Energy Resources in Pakistan”, Processes, vol. 7, pp. 118-124, 2019.

[10] Simon, Herbert Alexander., The New Science of Management Decision. New York: Harper, 1960.

[11]Laudon, C. K. and Laudon, J. P., "Management information systems", 7th Edition, Prentice Hall, New Jersey, 2002.

[12] Ballı, S., "Fuzzy çok kriterli karar verme ve basketbolda oyuncu seçimine uygulanması", Yüksek Lisans Tezi, Muğla Sitkı Koçman Üniversitesi Fen Bilimleri Enstitüsü, Muğla 2005.

[13] Cho K. T., "Multicriteria decision methods: an attempt to evaluate and unify,".Matematical and Computer Modelling, vol. 37, pp. 1099-1119, 2003.

[14] Chatterjee P., Athawale V. M., and Chakraborty S., "Selection of industrial robots using compromise ranking and outranking methods," Robotics and Computer-Integrated Manufacturing, vol. 26, pp. 480-489, 2010.

[15]Hwang, C. L. andYoon, P., "Multiple Attribute Decision Making In: Lecture Notes in Economics and Mathematical Systems," Springer-Verlag, Berlin, 1981.

[16] Mohammadshahi, Y. "A state-of-art survey on TQM applications using MCDM techniques," Decision Science Letters, vol. 2, no. 3, pp. 125-134, 2013.

[17]Deng, H., Yeh, C.H. and Willis, R.J., "InterCompany Comparison Using Modified TOPSIS with Objective Weights" Computers \& Operations Research, vol. 27, pp. 963-973, 2000.

[18] Jahanshahloo, G.R., Lotfi, F.H. and Izadikhah, M. "An Algorithmic Method to Extend TOPSIS for Decision-Making Problems with Interval Data" Applied Mathematics and Computation, vol. 175, pp. 1375-1384, 2006.

[19] Chamodrakas, I.,Leftheriotis, I. and Martakos, D., "In-Depth Analysis and Simulation Study of an Innovati ve Fuzzy Approach for Ranking Alternatives in Multiple Attribute Decision Making Problems Based on TOPSIS,"Applied Soft Computing, vol. 11, pp. 900-907,2011. 